\title{
Atypical Sensory Characteristics in Autism Spectrum Disorders
}

\author{
Yoshiro Morimoto $^{1,2} \bullet$ Akira Imamura $^{1}$ - Naoki Yamamoto ${ }^{1,2} \bullet$ \\ Shinji Kanegae ${ }^{1} \cdot$ Hiroki Ozawa1,2 $^{1, \text { Ryoichiro Iwanaga }^{3}}$ \\ ${ }^{1}$ Child and Adolescent Psychiatry Community Partnership Unit, Nagasaki University \\ Hospital, Nagasaki, Japan; ${ }^{2}$ Department of Neuropsychiatry, Unit of Translation Medicine, \\ Nagasaki University Graduate School of Biomedical Sciences, Nagasaki, Japan; ${ }^{3}$ School of \\ Health Science, Faculty of Medicine, Nagasaki University, Nagasaki, Japan
}

Author for correspondence: Akira Imamura, Child and Adolescent Psychiatry Community Partnership Unit, Nagasaki University Hospital, Nagasaki, Japan.

Email: aimamura@nagasaki-u.ac.jp

Doi: https://doi.org/10.36255/exonpublications.autismspectrumdisorders.2021.

atypicalsensorycharacteristics

\begin{abstract}
Autism spectrum disorders (ASD) are characterized by atypical cognitive, social, emotional, and perceptual functioning. An increasing body of evidence suggests that patients with ASD exhibit atypical perceptual and information processing in the auditory, visual, and tactile domains. However, the detailed characteristics of this atypical sensory functioning have not been fully elucidated. This chapter provides a comprehensive review of recent research into sensory processing in individuals with ASD, using a range of neuropsychological and neurophysiological techniques. Electroencephalography studies have reported atypical electrophysiological findings during sensory processing of visual, auditory, and tactile stimulation in individuals with ASD. In addition, functional magnetic resonance imaging studies have begun to elucidate the neural areas underlying these characteristic differences in sensory functioning. Several approaches, including environmental design, and support for parents and teachers to understand
\end{abstract}

In: Autism Spectrum Disorders. Grabrucker AM (Editor). Exon Publications, Brisbane, Australia. ISBN: 978-0-6450017-8-5; Doi: https://doi.org/10.36255/exonpublications. autismspectrumdisorders. 2021

Copyright: The Authors.

License: This open access article is licenced under Creative Commons Attribution-NonCommercial 4.0 International (CC BY-NC 4.0) https://creativecommons.org/licenses/by-nc/4.0/ 
and respond to atypical sensory characteristics associated with ASD have been developed. Increasing understanding of the neurobiological processes underlying sensory problems in patients with ASD will aid the development of new treatment approaches.

Keywords: autism spectrum disorders; electroencephalography; functional magnetic resonance imaging; magnetoencephalography; sensory function

\section{INTRODUCTION}

Three classes of atypical perceptual phenomena have consistently been associated with autism spectrum disorders (ASD): superior processing of fine detail (local structure), either inferior processing of overall/global structure or an ability to ignore disruptive global/contextual information, and impaired motion perception (1). Atypical sensory features in ASD were first described by Kanner (2). Numerous subsequent studies have documented the neurophysiological profiles of sensory processing in $\operatorname{ASD}(2,3)$. Unlike previous editions, the Diagnostic and Statistical Manual of Mental Disorders, Fifth Edition (DSM-5) adopted sensory characteristics as a diagnostic criterion for ASD (4). The DSM-5 assesses the atypical sensory characteristics of ASD patients in terms of hypersensitivity or hypo-reactivity to sensory input or abnormal interest in sensory aspects of the environment. Thus, in the DSM-5, overlooking atypical sensory characteristics can cause problems in the diagnostic process.

\section{CLASSIFICATION OF SENSORY CHARACTERISTICS}

Dunn's Four Quadrant Model (5) is the best-known model for classifying the sensory characteristics of ASD. In this model, sensory processing is based on two major components: neurological thresholds and behavioral responses. Neurological thresholds are response thresholds to sensory stimuli, expressed as a continuous range from low to high. Each person has unique thresholds for responding to sensory information, and thresholds may not be the same for all sensory modalities. Behavioral responses are expressed in a continuous range, depending on whether a passive or active strategy is selected for the stimulus. These two components make up the four quadrants of the model (6), explaining the processing of sensory information in children with ASD through an interaction between stimulus volume and reactive behavior/self-regulation. Disruption of an individual's sensory processing ability can affect their daily life (7).

Sensory processing disorder (SPD) is defined as a condition in which a person encounters problems in daily life related to processing and responding to sensory information (8). Using a standardized sensory processing assessment method such as Dunn's Sensory Profile (9), clinicians typically consider scores outside the first and second standard deviations as indicating likely or suspected SPD. SPD has been reported to affect at least 5\% of the general population (10). 
The frequency of atypical sensory characteristics in children with ASD is estimated at approximately $90 \%$, and the frequency of auditory hypersensitivity is reported to be $15-100 \%$ (11). Because the atypical sensory characteristics of children with ASD vary greatly from person to person, supporters need to understand the severity of symptoms and difficulties for each individual. Atypical sensory features are found in multiple sensory domains (12). Sensory problems in ASD have been reported to be associated with many of the core symptoms of ASD and other symptoms such as anxiety, attention problems, self-injury, behavioral problems, sleep disturbances, and gastrointestinal symptoms (13, 14). Sensory problems have also been reported to be associated with emotional and behavioral disruption and interference with daily functioning $(5,15)$. Therefore, assessing sensory problems in infancy and providing appropriate care may be helpful for later social behavioral development. Individuals with ASD show elevated sensory modulation symptoms across ages and levels of severity. In addition, reported sensory differences between ASD and typical groups are highest for participants aged 6-9 years (16), raising an important issue for school staff who provide learning environments for children. Because sensory information forms a component of higher-order social and cognitive functioning, atypical sensory processing in children with ASD is not only a new additional component of the diagnostic criteria but also an important cornerstone for characterizing and understanding ASD (16).

\section{EVALUATION METHODS}

There are several methods for quantifying atypical sensory deficits in patients with ASD. In this section, we summarize recent findings regarding each method.

\section{Questionnaire-based evaluations and behavioral observation methods}

The Sensory Profile (17) is a standardized scale used to record the way children with ASD respond to sensory experiences. Dunn et al. used the Sensory Profile to show that children with ASD have difficulty responding appropriately to stimuli and regulating their emotional responses (18). Watling et al. reported that $85 \%$ of young children with ASD scored lower than non-autistic children on at least one of the elements of the Sensory Profile (19). In addition, several studies have reported that children with autism have lower scores on the Under-responsive/ Seeks Sensation, Auditory Filtering, and Tactile Sensitivity sections of the Short Sensory Profile (SSP) $(20,21)$.

Studies with young children have reported significant correlations between SSP scores and stereotyped interest and behavior scores on the Autism Diagnostic Observation Schedule (ADOS), but no correlations have been found with social and communication scores on the $\operatorname{ADOS}(22,23)$. Similarly, one study reported correlations between sensory processing scores on the SSP and repetitive and restricted behavior scores on the ADOS, but not with social and communication scores on the ADOS, in children with autism (24). Rating scales such as the 
Aberrant Behavior Checklist-Community (ABC-C) (25) and Vineland Adaptive Behavior Scales (VABS) (26) are commonly used to quantify problematic, abnormal, and adaptive behaviors in ASD patients. Using the ABC-C, Green et al. reported that young developmentally disabled children exhibit persistent and high frequencies of abnormal behavior (27). Jasmin et al. used the VABS to investigate the relationship between sensory processing and daily living skills in children with ASD and found that sensory avoidance was significantly correlated with daily living skills (28).

\section{Neuropsychological acoustic startle reactivity test}

In studies of sensitivity to sensory stimuli in ASD, the acoustic startle response has been used as an objective measure of sensitivity to auditory stimuli. In ASD, an increase in startle magnitude, which indicates greater auditory sensitivity, has been reported in both adults and children (29-31). However, there are no other reports of a general increase in the magnitude of the startle response in ASD subjects (32-36). In a study that took into account the severity of ASD, increased startle magnitude was reported to be specific to individuals with high-functioning ASD (29). Adult ASD subjects have been reported to show increased startle responses to pleasant stimuli, but not to neutral or unpleasant stimuli $(37,38)$. In addition, ASD subjects have been reported to exhibit not only an increase in startle magnitude, but also an increase in startle latency (39).

Like startle magnitude, the severity of ASD symptoms may influence startle latency. High-functioning individuals with ASD have been reported to exhibit greater startle magnitude but no change in startle latency (32). Overall, these studies suggest increased sensitivity to auditory stimuli and altered sensory processing in ASD subjects. However, further research is needed to clarify which stimuli and parameters have the greatest impact on the sensory responses of ASD subjects.

Prepulse inhibition (PPI) is an additional startle measure that has been investigated in ASD, taking advantage of the acoustic startle response to quantify sensorimotor gating. In studies of adults and children with autism, multiple studies have reported unchanged PPI $(29,31,36,39,40)$. However, other studies have reported decreased PPI in adults $(33,41)$. In addition, one study reported a slight increase in PPI levels at $76 \mathrm{~dB}$ prepulse in autistic children aged 8-12 years (42). Although it is possible that heterogeneity in experimental design between studies has prevented reliable detection of subtle PPI disturbances in ASD, there is currently little evidence to suggest that changes in PPI are a robust feature of ASD.

\section{Auditory electroencephalography}

Orekhova and Stroganova recently reviewed auditory event-related potential (ERP) studies in ASD, suggesting the potential hypothesis that the dampening of responses of ASD patients to unattended sensory events is related to a deficit in rapid arousal processes (43). Donkers et al. sought to relate auditory ERPs to patterns of sensory symptoms in children with ASD aged 4 to 12 years with a range of levels of cognitive ability. The researchers reported that, although there was no ERP component that predicted sensory symptom patterns, there were complex 
associations between auditory ERPs and sensory symptom patterns, and both bottom-up (early sensory) and top-down (attention) influences on the severity of sensory symptoms in ASD (44).

\section{Visual electroencephalography}

Previous findings regarding visual processing in ASD have been mixed. Isler et al. reported that ASD patients are characterized by hypersensitivity to flashing light stimuli, strong and fast initial visual evoked responses, and slow recovery from stimuli (45). Frey et al. assessed sensory responses to stimuli presented in the visual center and visual periphery, reporting that ASD patients exhibit enhanced sensory responses to the visual periphery (46). Visual evoked responses to grating stimuli suggest a dissociation between hyper- and hypo-responsiveness based on spatial frequency, with high and low spatial frequency stimuli yielding increased and decreased responses, respectively $(47,48)$. Studies of visual evoked responses to grating stimuli suggest that reactivity increases with high spatial frequency stimuli, whereas it decreases with low spatial frequency stimuli $(47,48)$. In addition, one study suggested that hypo-responsiveness may be restricted to the right hemisphere (48). In studies using a visual oddity task to investigate the late components of visual processing, cortical hypersensitivity to visual change was found regardless of whether the task was active in high-functioning ASD (49) or passive in ASD patients with various levels of cognitive ability (50). Milne et al. used electroencephalography to analyze brain processes in visual perception and reported that ASD patients and controls exhibited different processing in the striate or extrastriate cortex and cingulate gyrus (51). It has also been reported that the synchrony of visual areas between the right and left hemispheres is reduced in patients with ASD (52).

\section{Tactile electroencephalography}

Cascio et al. reported that early neural responses to tactile stimuli were associated with tactile hyper-responsiveness, while slightly later neural responses were associated with tactile hypo-responsiveness, and speculated that higher-order processes, such as attention allocation and emotional value assignment, may be involved (53).

In summary, recent EEG studies have demonstrated differences in the timing of responses to auditory, visual, and tactile input in patients with ASD. Furthermore, these findings suggest that both bottom-up and top-down processes are affected. Future attempts to correlate EEG with sensory stimuli may be useful for building a model for integrating neural and symptom perspectives.

\section{Auditory functional magnetic resonance imaging}

Compared with EEG, relatively few functional magnetic resonance imaging (fMRI) studies have examined neural responses to sensory stimuli. Gomot et al. reported two auditory oddball fMRI studies on passive and active listening tasks $(54,55)$. Children and adolescents with ASD exhibited less brain activation during passive tasks and greater brain activation during active tasks in response to deviant and 
novel stimuli. These results demonstrate the presence of attention-dependent atypicality (both hypo-responsiveness (54) and hyper-responsiveness (55)) to auditory stimuli in ASD patients.

\section{Visual fMRI}

An fMRI study of visual stimulation in children with ASD, their healthy siblings, and controls reported decreased activation of attentional networks in children with ASD (56). Clery et al. used fMRI to analyze visual change detection in groups of adults with and without ASD, and reported that adults with ASD exhibited increased activation in the visual cortex and decreased activation in the frontal lobe in response to deviant and novel stimuli (57). Ohta et al. used fMRI to investigate sensory filtering in response to irrelevant visual distractors during a visual target detection task and reported that visual disturbances had less impact on visual cortex activity in ASD patients compared with controls (58).

\section{Tactile fMRI}

Kaiser et al. examined neural responses to arm or palm touch and reported increased responses in the primary somatosensory cortex and insular cortex and increased reactivity to non-social contact in patients with ASD (59). Cascio et al. reported increased activation of attentional areas in ASD patients compared with controls, when presented with disagreeable rather than pleasant tactile stimuli (60). These findings suggest that ASD patients exhibit increased neural reactivity to tactile stimuli compared with healthy individuals. However, the detailed mechanisms by which this hyperreactivity is triggered remain unclear.

\section{Multiple fMRI Modalities}

Green et al. reported greater activation of primary sensory cortex, amygdala, hippocampus, and orbitofrontal cortex in patients with ASD, compared with controls, when presented with aversive auditory and tactile stimuli during fMRI scans (61). They conducted an additional analysis of the specific role of visual and tactile sensory hypersensitivity symptoms in ASD, highlighting the importance of sensorilimbic hypersensitivity and prefrontal downregulation of amygdala in the symptoms (62).

In summary, very few fMRI studies have examined neural response patterns to sensory stimuli. However, the studies presented above have the potential to increase current understanding of how the brain responds when processing auditory, visual, and tactile stimuli. Although fMRI studies of sensory stimuli have consistently reported atypical response patterns in ASD patients, some have reported increased responsiveness, while others have reported reduced responsiveness. Thus, more comprehensive findings will be needed to clarify this issue.

\section{Magnetoencephalography (MEG)}

Several MEG studies have examined sensory processing in ASD. Resolution at $50 \mathrm{~ms}$ post-stimulus (M50) and at $100 \mathrm{~ms}$ post-stimulus (M100) are important 
targets for MEG studies. Roberts et al. performed an MEG study on auditory processing and reported that the M100 latency was delayed in ASD patients (63). The P100 component at around $100 \mathrm{~ms}$ after stimulation is the most prominent component of the auditory evoked magnetic field response in children (64). Orekhova et al. reported atypical hemispheric lateralization of the P100 in ASD patients measured using MEG in a paired click paradigm (65). Marco et al. used a finger-tapping paradigm to examine the timing and amplitude of responses in primary somatosensory cortex and reported that children with ASD exhibited reduced amplitude in the left and right cerebral hemispheres and prolonged latency in the right hemisphere (66). These MEG-based sensory stimulation studies indicate that there may be differences in the maturity and laterality of sensory processing in ASD patients. However, the number of MEGbased sensory stimulation studies is still small, and more research will be needed to clarify this issue.

\section{TREATMENT OF SENSORY PROBLEMS}

Treatment plans for atypical sensory problems in children with ASD can include behavioral interventions, other therapies, medications, or a combination of these approaches. In this section, we present some common treatment options.

\section{Interventions targeting sensory problems in ASD}

A number of sensory-based interventions have been investigated for treating sensory problems in ASD: (i) sensory integration-based interventions; (ii) environmental enrichment-based interventions; (iii) auditory integration-based interventions; (iv) music therapy-based interventions; (v) massage-based interventions; and (vi) other/additional interventions outside the broader categories. Although these therapies are considered effective, few studies have validated their efficacy $(67,68)$. A variety of methods have been developed for treating sensory challenges. These interventions are expected to produce improvements for atypical sensory deficits and ASD symptoms in ASD patients. However, to date, no evidence-based interventions have been reported to provide long-term and sufficient improvement.

\section{Caregivers' understanding of symptoms and cooperative attitudes toward treatment}

Patients and their supporters need to have an accurate understanding of the characteristics of sensory problems. In cases where ASD children and their families are unaware of atypical sensory problems, more detailed and specific explanations need to be provided. Teachers must be aware of the sensory challenges of students with ASD and the resulting anxiety and social life difficulties they may experience. When teachers understand both the social and sensory needs of ASD students, they can make the necessary adjustments (e.g., avoiding crowded spaces and loud noises) to reduce the stress of ASD students. 


\section{Emotional stabilization of patients}

Pfeiffer et al. reported an association between sensory sensitivity and anxiety in children and teens with ASD (69). This result is consistent with the results of a study of children in Japan (70). A recent study by Joosten and Bundy reported that children with ASD and intellectual disability demonstrated sensory processing abilities that likely contributed to increased anxiety (71). Another study reported that, when ASD patients with sensory hypersensitivity experience high anxiety, their hypersensitivity becomes even more pronounced (72). Because sensory sensitivity and anxiety have been suggested to exacerbate each other, therapists should consider environmental adaptations that minimize sensory discomfort and help the patient feel safe and comfortable (e.g., sensitivity to light and sound).

\section{Using tools to reduce sensory stimuli}

Tools to reduce sensory stimuli that induce discomfort and inappropriate behavior in ASD patients can be relatively easily implemented. For patients with visual sensitivity, the use of sunglasses may be helpful. Similarly, for patients with hearing sensitivity, earplugs or noise-canceling earphones may be helpful. Ikuta et al. reported the supportive effects of standard earmuffs and noise-canceling headphones on auditory stimulation in children with ASD (73). However, patients with coexisting tactile hypersensitivity may find it difficult to use such devices for a long period of time. Thus, the development of tools with good usability is important.

\section{CONCLUSION}

This chapter provides a general description of the assessment and support for sensory issues in ASD patients. When providing support for sensory difficulties in ASD patients, understanding not only the biological characteristics but also the psychological and social aspects of these phenomena can enable more effective support. Supporters (e.g., medical personnel, teachers, and daycare staff) need to understand the individual's situation and create environments where individuals with ASD can feel comfortable learning coping skills. Few neurophysiological studies have examined sensory problems, and there is a lack of established evidence for supportive methods. Therefore, a better understanding of the neurobiological aspects of sensory problems in individuals with ASD will aid the development of new treatments.

Acknowledgments: We thank Benjamin Knight, MSc., from Edanz (https:// jp.edanz.com/ac) for editing a draft of this manuscript. This work was supported by JSPS KAKENHI (grant numbers 20K16650) and the Takeda Science Foundation (to YM).

Conflict of interest: The authors declare no potential conflicts of interest with respect to research, authorship and/or publication of this manuscript. 
Copyright and permission statement: The authors confirm that the materials included in this chapter do not violate copyright laws. Where relevant, appropriate permissions have been obtained from the original copyright holder(s), and all original sources have been appropriately acknowledged or referenced.

\section{REFERENCES}

1. Dakin S, Frith U. Vagaries of visual perception in autism. Neuron. 2005;48(3):497-507. https://doi. org/10.1016/j.neuron.2005.10.018

2. Kanner L. Autistic disturbances of affective contact. Nervous Child. 1943;2:217-50.

3. Marco EJ, Hinkley LB, Hill SS, Nagarajan SS. Sensory processing in autism: A review of neurophysiologic findings. Pediatr Res. 2011;69(5 Pt 2):48R-54R. https://doi.org/10.1203/PDR.0b013e3182130c54

4. Diagnostic and statistical manual of mental disorders. 5th ed (DSM-5). Arlington, VA: American Psychiatric Association. 2013.

5. Dunn W. The Impact of Sensory Processing Abilities on the Daily Lives of Young Children and Their Families: A Conceptual Model. Infants \& Young Children. 1997;9(4):23-35 https://doi. org/10.1097/00001163-199704000-00005

6. Dunn W. Supporting children to participate successfully in everyday life by using sensory processing knowledge. Infants Young Child. 2007;20:84-101. https://doi.org/10.1097/01. IYC.0000264477.05076.5d

7. Koenig KP, Rudney SG. Performance challenges for children and adolescents with difficulty processing and integrating sensory information: A systematic review. Am J Occup Ther. 2010;64(3):430-42. https://doi.org/10.5014/ajot.2010.09073

8. SPD Foundation. (n.d.). About SPD. http://spdfoundation.net/index.php/about-sensory-processingdisorder/ [Accessed on 22 January 2019]

9. Dunn W, Brown C. Factor analysis on the Sensory Profile from a national sample of children without disabilities. Am J Occup Ther. 1997;51(7):490-9. https://doi.org/10.5014/ajot.51.7.490

10. Ahn RR, Miller LJ, Milberger S, McIntosh DN. Prevalence of parents' perceptions of sensory processing disorders among kindergarten children. Am J Occup Ther. 2004;58(3):287-93. https://doi. org/10.5014/ajot.58.3.287

11. Gomes E, Pedroso FS, Wagner MB. Auditory hypersensitivity in the autistic spectrum disorder. Pro Fono. 2008;20(4):279-84. https://doi.org/10.1590/S0104-56872008000400013

12. Marco EJ, Hinkley LB, Hill SS, Nagarajan SS. Sensory processing in autism: A review of neurophysiologic findings. Pediatr Res. 2011;69(5 Pt 2):48R-54R. https://doi.org/10.1203/PDR.0b013e3182130c54

13. Hazen EP, Stornelli JL, O'Rourke JA, Koesterer K, McDougle CJ. Sensory symptoms in autism spectrum disorders. Harv Rev Psychiatry. 2014;22(2):112-24. https://doi.org/10.1097/01. HRP.0000445143.08773.58

14. Schaaf RC, Lane AE. Toward a best-practice protocol for assessment of sensory features in ASD. J Autism Dev Disord. 2015;45(5):1380-95. https://doi.org/10.1007/s10803-014-2299-z

15. Schauder KB, Bennetto L. Toward an interdisciplinary understanding of sensory dysfunction in autism spectrum disorder: An integration of the neural and symptom literatures. Front Neurosci. 2016;10:268. https://doi.org/10.3389/fnins.2016.00268

16. Ben-Sasson A, Hen L, Fluss R, Cermak SA, Engel-Yeger B, Gal E. A meta-analysis of sensory modulation symptoms in individuals with autism spectrum disorders. J Autism Dev Disord. 2009;39(1):1-11. https://doi.org/10.1007/s10803-008-0593-3

17. Dunn W. Sensory Profile: User's manual. San Antonio, TX: Psychological Corporation. 1999. https:// doi.org/10.1037/t15155-000

18. Dunn W, Myles BS, Orr S. Sensory processing issues associated with Asperger syndrome: a preliminary investigation. Am J Occup Ther. 2002;56(1):97-102. https://doi.org/10.5014/ajot.56.1.97

19. Watling RL, Deitz J, White O. Comparison of Sensory Profile scores of young children with and without autism spectrum disorders. Am J Occup Ther. 2001;55(4):416-23. https://doi.org/10.5014/ ajot.55.4.416 
20. Baker AE, Lane A, Angley MT, Young RL. The relationship between sensory processing patterns and behavioural responsiveness in autistic disorder: A pilot study. J Autism Dev Disord. 2008;38(5):867-75. https://doi.org/10.1007/s10803-007-0459-0

21. McIntosh DN, Miller LJ, Shyu V. Development and validation of the Short Sensory Profile. In W Dunn (Ed.), Sensory Profile manual (pp. 59-73). San Antonio, TX: Psychological Corporation. 1999.

22. Wiggins LD, Robins DL, Bakeman R, Adamson LB. Brief report: Sensory abnormalities as distinguishing symptoms of autism spectrum disorders in young children. J Autism Dev Disord. 2009;39(7):1087-91. https://doi.org/10.1007/s10803-009-0711-x

23. Lord C, Rutter M, DiLavore P, Risi S. Autism Diagnostic Observation Schedule-WPS edition. Los Angeles, USA: Western Psychological Services. 1999. https://doi.org/10.1037/t17256-000

24. Rogers SJ, Hepburn S, Wehner E. Parent reports of sensory symptoms in toddlers with autism and those with other developmental disorders. J Autism Dev Disord. 2003;33(6):631-42. https://doi. org/10.1023/B:JADD.0000006000.38991.a7

25. Aman MG, Singh NN. Aberrant Behavior Checklist-Community: Supplementary manual. East Aurora, NY: Slosson Educational Publications. 1994.

26. Sparrow, S. S., Balla, D. A., \& Cicchetti, D. V. The Vineland Adaptive Behavior Scales: Survey form manual. Circle Pines, MN: American Guidance Service. 1984.

27. Green VA, O'Reilly M, Itchon J, Sigafoos J. Persistence of early emerging aberrant behavior in children with developmental disabilities. Res Dev Disabil. 2005;26(1):47-55. https://doi.org/10.1016/j. ridd.2004.07.003

28. Jasmin E, Couture M, McKinley P, Reid G, Fombonne E, Gisel E. Sensori-motor and daily living skills of preschool children with autism spectrum disorders. J Autism Dev Disord. 2009;39(2):231-41. https://doi.org/10.1007/s10803-008-0617-z

29. Kohl S, Wolters C, Gruendler TO, Vogeley K, Klosterkötter J, Kuhn J. Prepulse inhibition of the acoustic startle reflex in high functioning autism. PLoS One. 2014;9(3):e92372. https://doi.org/10.1371/ journal.pone.0092372

30. Chamberlain PD, Rodgers J, Crowley MJ, White SE, Freeston MH, South M. A potentiated startle study of uncertainty and contextual anxiety in adolescents diagnosed with autism spectrum disorder. Mol Autism. 2013;4(1):31. https://doi.org/10.1186/2040-2392-4-31

31. Takahashi H, Komatsu S, Nakahachi T, Ogino K, Kamio Y. Relationship of the acoustic startle response and its modulation to emotional and behavioral problems in typical development children and those with autism spectrum disorders. J Autism Dev Disord. 2016;46(2):534-43. https://doi.org/10.1007/ sl0803-015-2593-4

32. Bernier R, Dawson G, Panagiotides H, Webb S. Individuals with autism spectrum disorder show normal responses to a fear potential startle paradigm. J Autism Dev Disord. 2005;35(5):575-83. https:// doi.org/10.1007/s10803-005-0002-0

33. McAlonan GM, Daly E, Kumari V, Critchley HD, van Amelsvoort T, Suckling J, et al. Brain anatomy and sensorimotor gating in Asperger's syndrome. Brain. 2002;125(Pt 7):1594-606. https://doi. org/10.1093/brain/awf150

34. Salmond $\mathrm{CH}$, de Haan M, Friston KJ, Gadian DG, Vargha-Khadem F. Investigating individual differences in brain abnormalities in autism. Philos Trans R Soc Lond B Biol Sci. 2003;358(1430):405-13. https://doi.org/10.1098/rstb.2002.1210

35. Sterling L, Munson J, Estes A, Murias M, Webb SJ, King B, Dawson G. Fear-potentiated startle response is unrelated to social or emotional functioning in adolescents with autism spectrum disorders. Autism Res. 2013;6(5):320-31. https://doi.org/10.1002/aur.1289

36. Yuhas J, Cordeiro L, Tassone F, Ballinger E, Schneider A, Long JM, et al. Brief report: Sensorimotor gating in idiopathic autism and autism associated with fragile X syndrome. J Autism Dev Disord. 2011;41(2):248-53. https://doi.org/10.1007/s10803-010-1040-9

37. Dichter GS, Benning SD, Holtzclaw TN, Bodfish JW. Affective modulation of the startle eyeblink and postauricular reflexes in autism spectrum disorder. J Autism Dev Disord. 2010;40(7):858-69. https:// doi.org/10.1007/s10803-009-0925-y

38. Wilbarger JL, McIntosh DN, Winkielman P. Startle modulation in autism: Positive affective stimuli enhance startle response. Neuropsychologia. 2009;47(5):1323-31. https://doi.org/10.1016/j. neuropsychologia.2009.01.025 
39. Ornitz EM, Lane SJ, Sugiyama T, de Traversay J. Startle modulation studies in autism. J Autism Dev Disord. 1993;23(4):619-37. https://doi.org/10.1007/BF01046105

40. Oranje B, Lahuis B, van Engeland H, Jan van der Gaag R, Kemner C. Sensory and sensorimotor gating in children with multiple complex developmental disorders (MCDD) and autism. Psychiatry Res. 2013;206(2-3):287-92. https://doi.org/10.1016/j.psychres.2012.10.014

41. Perry W, Minassian A, Lopez B, Maron L, Lincoln A. Sensorimotor gating deficits in adults with autism. Biol Psychiatry. 2007;61(4):482-6. https://doi.org/10.1016/j.biopsych.2005.09.025

42. Madsen GF, Bilenberg N, Cantio C, Oranje B. Increased prepulse inhibition and sensitization of the startle reflex in autistic children. Autism Res. 2014;7(1):94-103. https://doi.org/10.1002/aur.1337

43. Orekhova EV, Stroganova TA. Arousal and attention re-orienting in autism spectrum disorders: Evidence from auditory event-related potentials. Front Hum Neurosci. 2014;8:34. https://doi. org/10.3389/fnhum.2014.00034

44. Donkers FC, Schipul SE, Baranek GT, Cleary KM, Willoughby MT, Evans AM, et al. Attenuated auditory event-related potentials and associations with atypical sensory response patterns in children with autism. J Autism Dev Disord. 2015;45(2):506-23. https://doi.org/10.1007/s10803-013-1948-y

45. Isler JR, Martien KM, Grieve PG, Stark RI, Herbert MR. Reduced functional connectivity in visual evoked potentials in children with autism spectrum disorder. Clin Neurophysiol. 2010;121(12):2035-43. https://doi.org/10.1016/j.clinph.2010.05.004

46. Frey HP, Molholm S, Lalor EC, Russo NN, Foxe JJ. Atypical cortical representation of peripheral visual space in children with an autism spectrum disorder. Eur J Neurosci. 2013;38(1):2125-38. https://doi. org/10.1111/ejn. 12243

47. Vlamings PH, Jonkman LM, van Daalen E, van der Gaag RJ, Kemner C. Basic abnormalities in visual processing affect face processing at an early age in autism spectrum disorder. Biol Psychiatry. 2010;68(12):1107-13. https://doi.org/10.1016/j.biopsych.2010.06.024

48. Pei F, Baldassi S, Norcia AM. Electrophysiological measures of low-level vision reveal spatial processing deficits and hemispheric asymmetry in autism spectrum disorder. J Vis. 2014;14(11):3. https:// doi.org/10.1167/14.11.3

49. Baruth JM, Casanova MF, Sears L, Sokhadze E. Early-stage visual processing abnormalities in highfunctioning autism spectrum disorder (ASD). Transl Neurosci. 2010;1(2):177-87. https://doi. org/10.2478/v10134-010-0024-9

50. Cléry H, Bonnet-Brilhault F, Lenoir P, Barthelemy C, Bruneau N, Gomot M. Atypical visual change processing in children with autism: An electrophysiological study. Psychophysiology. 2013;50(3):240-52. https://doi.org/10.1111/psyp.12006

51. Milne E, Scope A, Pascalis O, Buckley D, Makeig S. Independent component analysis reveals atypical electroencephalographic activity during visual perception in individuals with autism. Biol Psychiatry. 2009;65(1):22-30. https://doi.org/10.1016/j.biopsych.2008.07.017

52. Isler JR, Martien KM, Grieve PG, Stark RI, Herbert MR. Reduced functional connectivity in visual evoked potentials in children with autism spectrum disorder. Clin Neurophysiol. 2010;121(12):2035-43. https://doi.org/10.1016/j.clinph.2010.05.004

53. Cascio CJ, Gu C, Schauder KB, Key AP, Yoder P. Somatosensory event-related potentials and association with tactile behavioral responsiveness patterns in children with ASD. Brain Topogr. 2015;28(6):895-903. https://doi.org/10.1007/s10548-015-0439-1

54. Gomot M, Bernard FA, Davis MH, Belmonte MK, Ashwin C, Bullmore ET, et al. Change detection in children with autism: An auditory event-related fMRI study. Neuroimage. 2006;29(2):475-84. https://doi.org/10.1016/j.neuroimage.2005.07.027

55. Gomot M, Belmonte MK, Bullmore ET, Bernard FA, Baron-Cohen S. Brain hyper-reactivity to auditory novel targets in children with high-functioning autism. Brain. 2008;131(Pt 9):2479-88. https://doi. org/10.1093/brain/awn172

56. Belmonte MK, Gomot M, Baron-Cohen S. Visual attention in autism families: "Unaffected" sibs share atypical frontal activation. J Child Psychol Psychiatry. 2010;51(3):259-76. https://doi. org/10.1111/j.1469-7610.2009.02153.x

57. Clery H, Andersson F, Bonnet-Brilhault F, Philippe A, Wicker B, Gomot M. fMRI investigation of visual change detection in adults with autism. Neuroimage Clin. 2013;2:303-12. https://doi.org/10.1016/j. nicl.2013.01.010 
58. Ohta H, Yamada T, Watanabe H, Kanai C, Tanaka E, Ohno T, et al. An fMRI study of reduced perceptual load-dependent modulation of task-irrelevant activity in adults with autism spectrum conditions. Neuroimage. 2012;61(4):1176-87. https://doi.org/10.1016/j.neuroimage.2012.03.042

59. Kaiser MD, Yang DY, Voos AC, Bennett RH, Gordon I, Pretzsch C, et al. Brain mechanisms for processing affective (and nonaffective) touch are atypical in autism. Cereb Cortex. 2016;26(6):2705-14. https://doi.org/10.1093/cercor/bhv125

60. Cascio CJ, Moana-Filho EJ, Guest S, Nebel MB, Weisner J, Baranek GT, et al. Perceptual and neural response to affective tactile texture stimulation in adults with autism spectrum disorders. Autism Res. 2012;5(4):231-44. https://doi.org/10.1002/aur.1224

61. Green SA, Rudie JD, Colich NL, Wood JJ, Shirinyan D, Hernandez L, et al. Overreactive brain responses to sensory stimuli in youth with autism spectrum disorders. J Am Acad Child Adolesc Psychiatry. 2013;52(11):1158-72. https://doi.org/10.1016/j.jaac.2013.08.004

62. Green SA, Hernandez L, Tottenham N, Krasileva K, Bookheimer SY, Dapretto M. Neurobiology of sensory overresponsivity in youth with autism spectrum disorders. JAMA Psychiatry. 2015;72(8):778-86. https://doi.org/10.1001/jamapsychiatry.2015.0737

63. Roberts TP, Khan SY, Rey M, Monroe JF, Cannon K, Blaskey L, et al. MEG detection of delayed auditory evoked responses in autism spectrum disorders: Towards an imaging biomarker for autism. Autism Res. 2010;3(1):8-18. https://doi.org/10.1002/aur.111

64. Oram Cardy JE, Ferrari P, Flagg EJ, Roberts W, Roberts TP. Prominence of M50 auditory evoked response over M100 in childhood and autism. Neuroreport. 2004 Aug 26;15(12):1867-70. https:// doi.org/10.1097/00001756-200408260-00006

65. Orekhova EV, Tsetlin MM, Butorina AV, Novikova SI, Gratchev VV, Sokolov PA, et al. Auditory cortex responses to clicks and sensory modulation difficulties in children with autism spectrum disorders (ASD). PLoS One. 2012;7(6):e39906. https://doi.org/10.1371/journal.pone.0039906

66. Marco EJ, Khatibi K, Hill SS, Siegel B, Arroyo MS, Dowling AF, et al. Children with autism show reduced somatosensory response: An MEG study. Autism Res. 2012;5(5):340-51. https://doi. org/10.1002/aur. 1247

67. Weitlauf AS, Sathe N, McPheeters ML, Warren ZE. Interventions targeting sensory challenges in autism spectrum disorder: A systematic review. Pediatrics. 2017;139(6):e20170347. https://doi. org/10.1542/peds.2017-0347

68. Wan Yunus F, Liu KP, Bissett M, Penkala S. Sensory-based intervention for children with behavioral problems: A systematic review. J Autism Dev Disord. 2015;45(11):3565-79. https://doi.org/10.1007/ sl0803-015-2503-9

69. Pfeiffer B, Kinnealey M, Reed C, Herzberg G. Sensory modulation and affective disorders in children and adolescents with Asperger's disorder. Am J Occup Ther. 2005 ;59(3):335-45. https://doi. org/10.5014/ajot.59.3.335

70. Tsuji H, Miyawaki D, Kawaguchi T, Matsushima N, Horino A, Takahashi K, Suzuki F, Kiriike N. Relationship of hypersensitivity to anxiety and depression in children with high-functioning pervasive developmental disorders. Psychiatry Clin Neurosci. 2009 ;63(2):195-201. https://doi. org/10.1111/j.1440-1819.2008.01916.x

71. Joosten AV, Bundy AC. Sensory processing and stereotypical and repetitive behaviour in children with autism and intellectual disability. Aust Occup Ther J. 2010;57(6):366-72. https://doi. org/10.1111/j.1440-1630.2009.00835.x

72. Lane SJ, Reynolds S, Dumenci L. Sensory overresponsivity and anxiety in typically developing children and children with autism and attention deficit hyperactivity disorder: cause or coexistence? Am J Occup Ther. 2012;66(5):595-603. https://doi.org/10.5014/ajot.2012.004523

73. Ikuta N, Iwanaga R, Tokunaga A, Nakane H, Tanaka K, Tanaka G. Effectiveness of Earmuffs and Noise-cancelling Headphones for Coping with Hyper-reactivity to Auditory Stimuli in Children with Autism Spectrum Disorder: A Preliminary Study. Hong Kong J Occup Ther. 2016;28(1):24-32. https://doi.org/10.1016/j.hkjot.2016.09.001 